\title{
Aplicação da ferramenta de Análise de Ciclo de Vida (ACV) no processo de tratamento de efluentes em uma lavanderia de beneficiamento de jeans
}

\author{
Application of Life Cycle Analysis (LCA) tool in the treatment \\ process of effluents in a laundry of jeans
}

Armando Dias Duarte

Gilson Lima da Silva²

\begin{abstract}
${ }^{1}$ Universidade Federal de Pernambuco Engenheiro de Produção (UFPE/CAA) Mestre em Engenharia Civil e Ambiental (UFPE/CAA) Doutorando em Engenharia Civil (UFPE) Pesquisador em Análise de Ciclo de Vida no Grupo de Gestão Ambiental Avançada (GAMA) Universidade Federal de Pernambuco (UFPE), Campus do Agreste (CAA), Caruaru (PE) armando01.dias@gmail.com
\end{abstract}

\footnotetext{
2 Docente do curso de Engenharia Civil da Universidade Federal de Pernambuco Campus Agreste - UFPE. Coordenador do Grupo de Gestão Ambiental Avançada (GAMA) Universidade Federal de Pernambuco (UFPE), Campus do Agreste (CAA), Caruaru (PE). glimasilva21@yahoo.com.br
}

Resumo

A temática de sustentabilidade na indústria têxtil ganha cada vez mais força, através da adoção de práticas e ferramentas de gestão ambiental como a Análise de Ciclo de Vida (ACV). O presente estudo teve como objetivo a aplicação da ferramenta de ACV na Estação de Tratamento de Efluentes (ETE) em uma Lavanderia de Beneficiamento de Jeans (LBJ) e comparar os danos ambientais e sociais relacionadas ao tratamento do Efluente Industrial (EI) gerado após o beneficiamento das peças. Através de visitas técnicas e relatórios disponibilizados pela organização, foi elaborado o Inventário de Ciclo de Vida (ICV) e após o uso do software SimaPro, verificou-se que o uso de produtos químicos inorgânicos, apresentam os principais poluentes nas categorias do estudo, com impactos acima de $90 \%$. A energia elétrica apresentou impactos significativos, o que sugere a adoção de alternativas como a redução do tempo de funcionamento dos equipamentos e métodos por gravidade.

Palavras-chave: Gestão ambiental. Análise de ciclo de vida. Tratamento de efluentes. Lavanderia de jeans.

\section{Abastract}

The sustainability theme in the textile industry wins force more and more, through the adoption of practices and tools of environmental administration as the Life Cycle Analysis (LCA). The present study had as objective the application of the tool of LCA in the Station of Treatment of Effluents (STE) in a Laundry of Improvement of Jeans (LIJ) and to compare the environmental and social damages related to the Industrial Effluents (IE) generated after the improvement of the pieces. Through technical visits and reports made available by the organization, the Inventory of Cycle of Life (ICL) was elaborated and after the use of the software SimaPro, was verified that the use of inorganic chemical products, they present the main ones pollutant in the categories of the study, with impacts above $90 \%$. The electric power presented significant impacts, what suggests the adoption of alternatives as the reduction of the time of operation of the equipments and methods for gravity.

Keywords: Environmental administration. Life cycle analysis. Effluent treatment. Laundry of jeans. 
1 Introdução

As empresas cada vez mais são pressionadas a mudar a postura diante dos mercados competitivos e internalizarem em seus processos e procedimentos questões que garantam a sustentabilidade ambiental, Bankuti e Bankuti (2014) defendem que o desempenho ambiental deve ser discutido, não somente na competitividade econômica, mas também na competitividade ambiental, logo diversas práticas ambientais iniciaram-se a partir dessa necessidade de produzir sem agredir o meio ambiente, porém nem todas essas ações trazem uma visão detalhada dos impactos ambientais decorrentes da produção de bens e serviços e nem tão pouco tentam compatibilizar os benefícios ambientais com os ganhos da empresa. Diante da crescente preocupação em relação ao monitoramento dos impactos ambientais causados pelos desperdícios dos processos produtivos, o que pode acarretar em danos ao meio ambiente, Both e Fischer (2017) afirmam que é um grande desafio a geração do crescimento econômico, lucro e renda sem gerar a degradação do meio ambiente e esses impactos gerados pelas atividades podem ser mínimos ou de grandes proporções, a depender da atividade desempenhada na organização, Martins, Escrivao Filho, e Nagano (2016) explicam que as empresas de grande porte adotam ferramentas de gestão ambiental, a partir de uma visão estratégica, que buscam alcançar um melhor desempenho ambiental e econômico, porém as pequenas e médias empresas, devido a critérios específicos de gestão, não conseguem utilizar esses mecanismos de forma a minimizar os impactos ambientais. Conforme a Associação Brasileira da Indústria Têxtil (ABIT) no ano de 2017 a indústria têxtil e de confecção Brasileira tem grande importância e destaque na economia mundial, sendo atualmente a "quinta maior indústria têxtil do mundo, o segundo maior produtor de denim e o terceiro na produção de malhas". E é um dos ramos empresariais que mais causam impactos ambientais com o lançamento de efluentes nos corpos hídricos.

A Análise de Ciclo de Vida (ACV) possui diversas atuações de acordo com a NBR ISO 14040 (2009), entre elas estão: avaliação de risco, desempenho ambiental, auditoria e avaliação de impacto. De Souza e Barbastefano (2011) afirmam que há várias razões para os estudos de ACV, entre elas estão a) o aumento da preocupação ambiental por parte da sociedade; b) adoção de práticas com o foco nos padrões da ISO 14044; c) o papel de organizações com iniciativa de ACV como a Unidade de Ensino e Pesquisa (UNEP), Society Environmental Toxicolog and Chemistry (SETAC), sociedades de estudo em ACV, International Society for Industrial Ecology e agências ambientais nacionais. No Brasil os estudos tiveram início, segundo Zapparoli (2011) nos anos 2000, com várias iniciativas entre elas o projeto Brasileiro de Inventário de Ciclo de vida (ICV), realizado pelo Inmetro, o Programa Brasileiro de Ciclo de Vida estabelecido pelo Conselho Nacional de Metrologia, Normalização e Qualidade Industrial (Conmetro). Willers, Rodrigues e Silva (2013) afirmam que no Brasil já é oferecido um vasto campo de oportunidades de aplicação da metodologia, tanto nos setores da indústria, agroindústria e na área acadêmica, contudo, o uso de ACV aplicado aos estudos de saneamento, em específico no tratamento de esgotos ainda é recente, onde há poucos trabalhos publicados no Brasil e na América Latina, contudo, a comunidade científica internacional desenvolve trabalhos por meio de incentivo da International Water Association (IWA) (Lopes et al., 2017). Trabalhos e estudos já foram desenvolvidos com a avaliação de desempenho de ETE com a técnica de ACV (Tillman, Svingby, \& Lundström, 1998; Hospid, Moreira, \& Feijoo, 2007; Gallego, Hospido, Moreira, \& Feijoo, 2008; Foley, Hassad, Hartleyb, \& Lant, 2010; Fuchs, Mihelcic, \& Gierke, 2011; Lopsik, 2013). Almeida e Bessa (2015) afirmam que um material ou 
processo possui diversos impactos ambientais e através da ACV é possível identificar como eles agravam os problemas ambientais do planeta. Assim, conservar as matérias-primas não renováveis, as fontes de energia, os sistemas ecológicos com déficit de suprimentos e as regiões com escassez de água podem ser o objetivo de um estudo sobre ACV. De acordo com Brito (2013) no Brasil existe cerca de 6.000 lavanderias, e estão subdivididas por setores de atuação com processos distintos: lavanderias hospitalares, lavanderias de hotéis, motéis, restaurantes, roupas profissionais e lavanderias de jeans (confecção). Sant'ana (2010) afirma que a Confederação Nacional de Indústrias considera a atividade têxtil como uma das mais impactantes no meio ambiente, durante seus processos industriais, sofrendo pressões ambientais pelo poder público e a comunidade. Conforme, a Confederação Nacional da Indústria (CNI, 2017), Pernambuco possui um PIB de 26, 9 bilhões, contribuindo com 2,3\% do PIB industrial nacional em 2015, conta com 1,1\% das indústrias de vestuário, enquanto a região Nordeste possui 1,5\% e o Brasil, 1,3\%. Em 2015 Pernambuco foi considerado o maior produtor têxtil e de confecções da região Nordeste, e o oitavo principal produtor do Brasil, sendo responsável por 47,5 mil empregos diretos e 1.359 empresas do setor têxtil (ABIT, 2015). O polo de confecções do agreste é considerado o segundo maior do país, conforme o Sindicato das Indústrias do Vestuário do Estado de Pernambuco - SINDVEST PE, o que representa 9\% da produção nacional de confecção (ABIT, 2016).

O setor de confecções no Nordeste é distribuído em diversos estados, encontrando-se principalmente nos estados do Ceará, Pernambuco, Rio Grande do Norte, Bahia e Paraíba. A etapa do beneficiamento do jeans segundo Lopes (2012) por utilizar substâncias excessivamente tóxicas possui um potencial elevado de impactos, constatando que algumas substâncias podem ser substituídas por outras que geram um impacto menor, no entanto com custos mais elevados ou menos eficazes. Com isso a procura de novas soluções passa a ser uma necessidade para o contínuo desenvolvimento sustentável.

A partir da problemática ambiental, o presente estudo teve como objetivo a aplicação da metodologia de ACV na Estação de Tratamento de Efluentes (ETE) em uma Lavanderia de Beneficiamento de Jeans (LBJ) localizada na cidade de Caruaru - PE de forma a analisar o efluente tratado, nas categorias de impacto: mudanças climáticas, eutrofização de água doce, eutrofização marinha, toxicidade humana e ecotoxicidade de água doce.

\section{Referencial teórico}

Segundo Coelho Filho, Saccarro Junior e Luedemann (2015) o processo de realização de um estudo de ACV é composto por quatro etapas sendo que a primeira e a última realizam análise qualitativa e a segunda e terceira fazem uma análise quantitativa. Segundo Marques, Gomes e Kern (2016) as quatro etapas da ACV dividem-se em determinar o propósito e escopo, onde se delimita a amplitude, domínio do trabalho, os métodos e a unidade utilitária; análise do inventário, onde se obtém as informações analisando os impactos que são estipulados pelos indicadores para a possibilidade de uma avaliação das informações. 
Conforme a norma NBR ISO 14040:2009 a avaliação deve incluir as seguintes etapas: (1) definição de objetivo e escopo, (2) análise de inventário, (3) avaliação de impacto e (4) interpretação dos resultados. Suas fases são descritas na figura 1:

Figura 1 - Fases de Avaliação do Ciclo de Vida

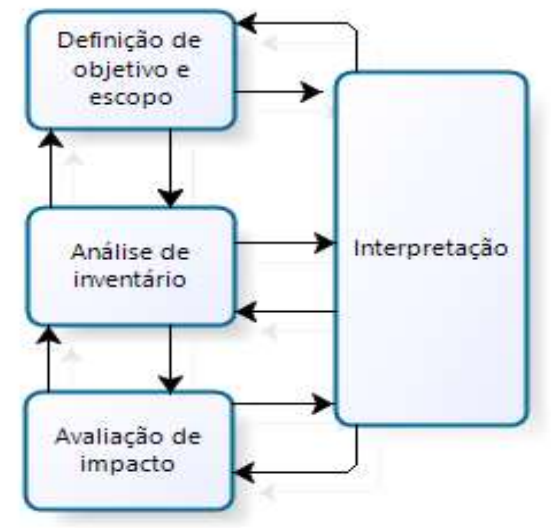

Fonte: NBR ISO 14040/2001.

O objetivo do estudo deve declarar a aplicação pretendida do estudo, as razões e o público-alvo. Segundo Claudino e Talamini (2013), o escopo do estudo é uma das fases mais importantes visto que o estudo é realizado de acordo com o estabelecido nesta etapa, que define o propósito do estudo, o resultado esperado, os limites do sistema, unidade funcional (UF) e as suposições. O escopo deve ser bem definido para assegurar a extensão, a profundidade e detalhe do estudo sejam compatíveis e suficientes para atender o objetivo estabelecido (NBR ISO 14040, 2009). Segundo a NBR ISO 14040:2009 o escopo da ACV deve especificar claramente as funções do sistema em estudo. Uma unidade funcional é uma medida do desempenho das saídas funcionais (está relacionado às saídas do sistema de produtos, que está relacionado à sua função, por exemplo, a água utilizada para o beneficiamento do jeans será analisada pela Demanda Química de Oxigênio) do sistema de produto. O propósito principal de uma unidade funcional é fornecer uma referência para a qual as entradas e saídas são relacionadas. Esta referência é necessária para assegurara comparabilidade de resultados da ACV. O fluxo de referência pode ser entendido como a medida das saídas de processos em um dado sistema de produto, requeridas para realizar a função expressa pela unidade funcional. As fronteiras do sistema determinam quais unidades de processos devem ser incluídas na ACV (NBR ISO 14040, 2009). Para a escolha dos fatores que irão delimitar as fronteiras do sistema, vários fatores devem ser levados em consideração, como por exemplo, a aplicação do estudo, as suposições, critérios de corte, restrições de dados e custo e o público - alvo pretendido. Para a modelagem do sistema é importante que a seleção das entradas e saídas da categoria de dados deve ser consistente com o objetivo do estudo. A modelagem deve ser feita de forma que as entradas e saídas nas fronteiras sejam fluxos elementares. A Avaliação dos Impactos do Ciclo de Vida (AICV) visa compreender e avaliar os impactos ambientais com base na análise de inventário no âmbito da meta e no escopo do estudo (Claudino \& Talamini, 2013). Essa 
etapa é fruto da junção da análise dos potenciais impactos e aos aspectos identificados na etapa de análise de inventário.

\section{Materiais e métodos}

Para atingir o objetivo foi realizado o estudo do fluxograma do processo de tratamento de efluentes através de visitas técnicas realizadas na empresa, e a coleta de dados para a elaboração do Inventário de Ciclo de Vida, foi obtida através de relatórios quantitativos do uso do consumo de produtos químicos e da qualidade do efluente através de relatórios fornecidos por uma empresa terceirizada. Foi utilizado o software Simapro ${ }^{\circledR}$ que permitiu avaliar os impactos ambientais do processo de tratamento de efluentes, dentro do seu âmbito de análise, pode-se identificar e avaliar tanto aspectos mais significativos quanto os de menor abrangência e por fim a análise dos resultados. De posse dessas análises foi possível incrementar as informações para os tomadores de decisões, por se tratar de uma metodologia internacionalmente reconhecida em diversos países, onde as principais referências de estudos sãos os norte-americanos e europeus, que contribuem para a consolidação da metodologia em todo o mundo (Willers, Rodrigues, \& Silva, 2013). As etapas produtivas foram destrinchadas e analisadas em função dos tipos e quantidades de entradas e saídas, onde foi possível visualizar o fluxo de energia, matérias primas e rejeitos antes, durante e após a realização dos processos produtivos, o que permitiu determinar onde e como os possíveis impactos ambientais são originados. Neste processo foram analisadas as emissões para água, solo e ar decorrentes da produção, utilização e disposição final avaliando-se o impacto ambiental associado ao uso dos recursos naturais, emissões de poluentes e identificação de oportunidades para melhorar o sistema, de forma a otimizar o desempenho ambiental do produto. Além disto, a ACV pode ser conceituada como ferramenta para avaliar os efeitos ambientais de um produto, processo ou atividade ao longo do seu ciclo de vida ou duração, conhecido como análise "do berço ao túmulo" (Claudino \& Talamini, 2013).

\subsection{Caracterização do estudo de caso}

O município de Caruaru está localizado na mesorregião do Vale do Ipojuca possui uma área territorial de 921 quilômetros quadrados representando 0.94\% da área do Estado de Pernambuco. Possui uma população residente de aproximadamente 314.951 habitantes (IBGE, 2014). Além disso, os municípios de Toritama e Santa Cruz, situados na microrregião do Alto do Capibaribe, fazem parte do Arranjo Produtivo Local de Confecções do Agreste Pernambucano (APLCAPE). As micros e pequenas empresas que compõe o APLCAPE se destacam por fabricarem e exportarem diferentes tipos de roupas, onde podemos encontrar Lavanderias de Beneficiamento de Jeans (LBJ) que utilizam grandes quantidades de recursos naturais, como madeira para a queima da caldeira, e para o tingimento das peças de jeans, são utilizadas grandes quantidades de água em conjunto com produtos químicos em diferentes processos. Segundo Silva (2013) as LBJ juntas que compõe o APLCAPE representam mais 
de 200 unidades industriais de diversos portes e capacidades produtivas, em sua grande maioria são empresas de pequeno porte e de caráter familiar que segundo a classificação do SEBRAE (2015) possui entre 10 a 49 funcionários. A grande maioria se encontra nas cidades de Caruaru (83 empresas) e Toritama (77 empresas). Foram realizadas visitas técnicas às lavanderias da região para identificar suas principais características (de gestão, ambientais, de segurança, etc.). A escolha da lavanderia do estudo deve-se ao fato de possibilitar uma maior recepção com a universidade por parte do proprietário e a disponibilidade de fornecer dados para a pesquisa. Na fase de caracterização também foi importante o conhecimento das informações históricas da lavanderia. A empresa é caracterizada por ser uma lavanderia de origem familiar. O trabalho é feito nos três turnos, seis dias por semana. Para o beneficiamento do jeans, as peças são submetidas a diversas operações onde a maioria dos processos ocorre no meio aquoso, chamado de banhos, onde são adicionados produtos químicos para as especificações dos pedidos (SILVA, 2013). Para a produção de um quilo de tecido no setor têxtil são necessários cerca de 150 litros de água (ABIT, 2005; Ueda, 2006) e aproximadamente 200 litros de água (Ratiu, Bota., e Suteu, 2008). Em 2006 a empresa Levi's tornou público a ACV de um par de calça jeans cujo consumo equivale a 3.482 litros de água, equivalente a deixar uma mangueira ligada por 106 minutos (Figueiredo \& Cavalcanti, 2010), contudo no estudo realizado, não foi especificado os processos de produção da calça jeans.

\subsection{Atividades de consumo de água}

As etapas das operações que são utilizadas para o beneficiamento úmido realizado dentro da lavanderia do estudo estão descritas na figura 2:

Figura 2 - Fluxograma do beneficiamento de jeans

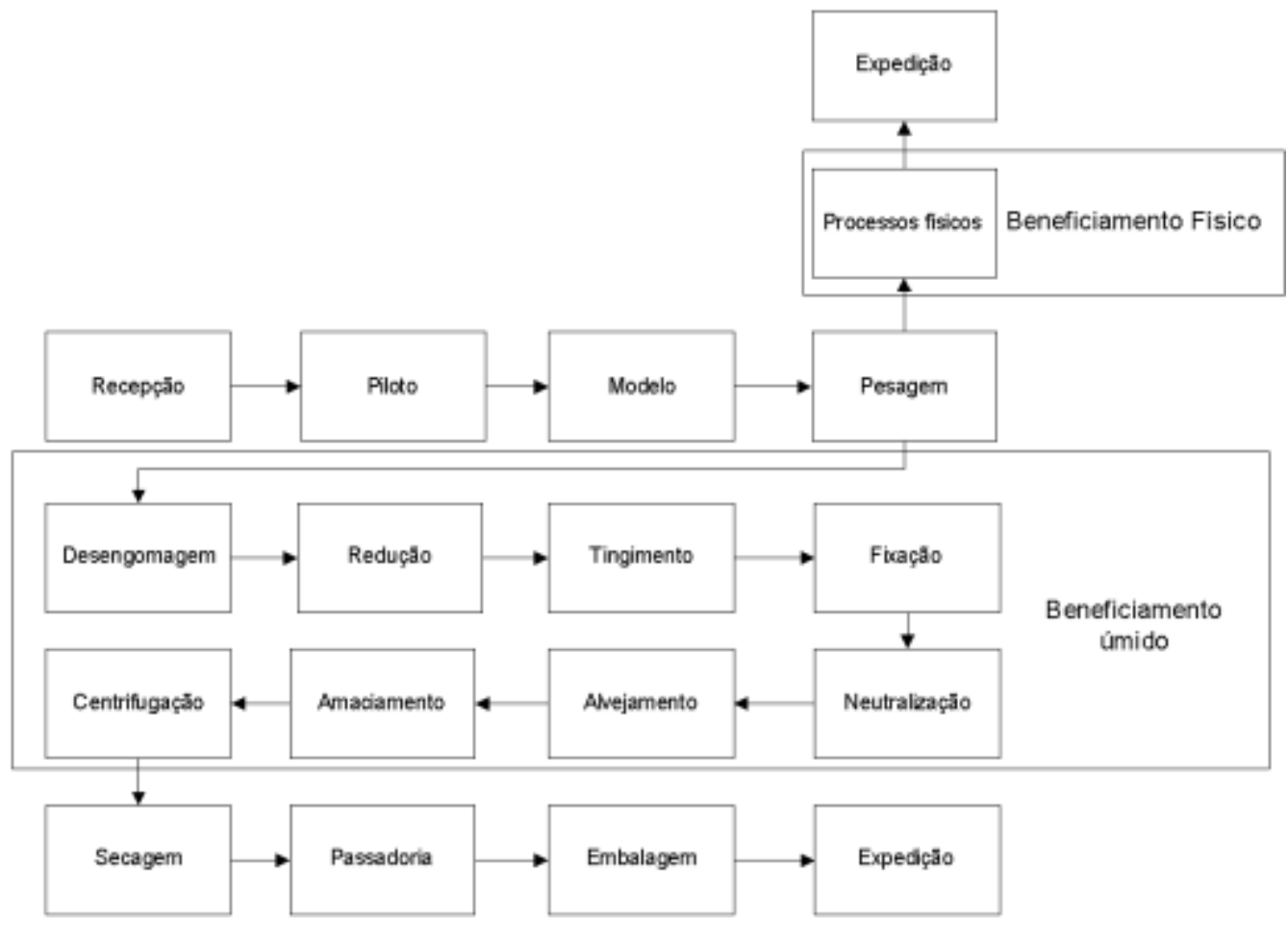

Fonte: Autores. 
Segundo Silva (2013) são utilizados dois tipos de águas para as demandas internas: a água para o consumo humano e para a produção. No setor da produção a água é utilizada para a geração de vapor, lavagem de gases da caldeira, na higienização dos ambientes e nas operações. A figura 3 demonstra o macro fluxo de água na lavanderia do estudo sem levar em consideração os detalhes internos dos processos produtivos. As principais fontes de abastecimento da lavanderia do estudo são provenientes da concessionária local, a compra de caminhões do tipo pipa, e dois poços artesanais.

Figura 3 - Macro fluxo da água na lavanderia

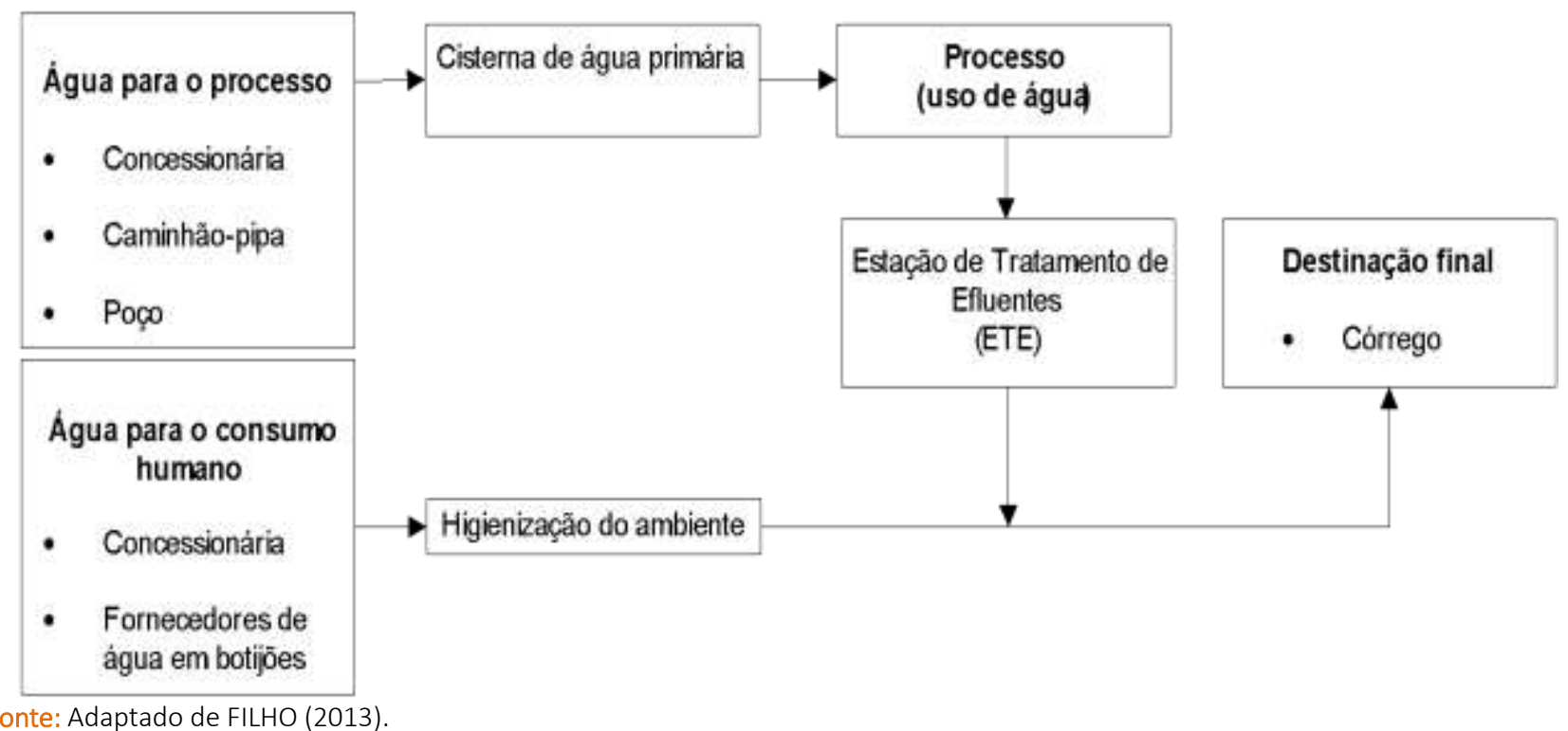

Fonte: Adaptado de FILHO (2013).

\subsection{Aplicação do ACV}

No presente trabalho foi utilizado o software de ACV desenvolvido pela empresa holandesa Pré Consultant, SimaPro ${ }^{\circledR}$ (versão Faculty) que segue as fases da ACV descritas pela ISO 14040. O software foi escolhido após verificações de outros programas na área e constatado que é o mais utilizado por indústrias e trabalhos acadêmicos, além de apresentar os principais bancos de dados de inventários de ciclo de vida. O sistema do estudo está descrito na figura 5 : 
Figura 5 - Fluxograma do sistema do estudo

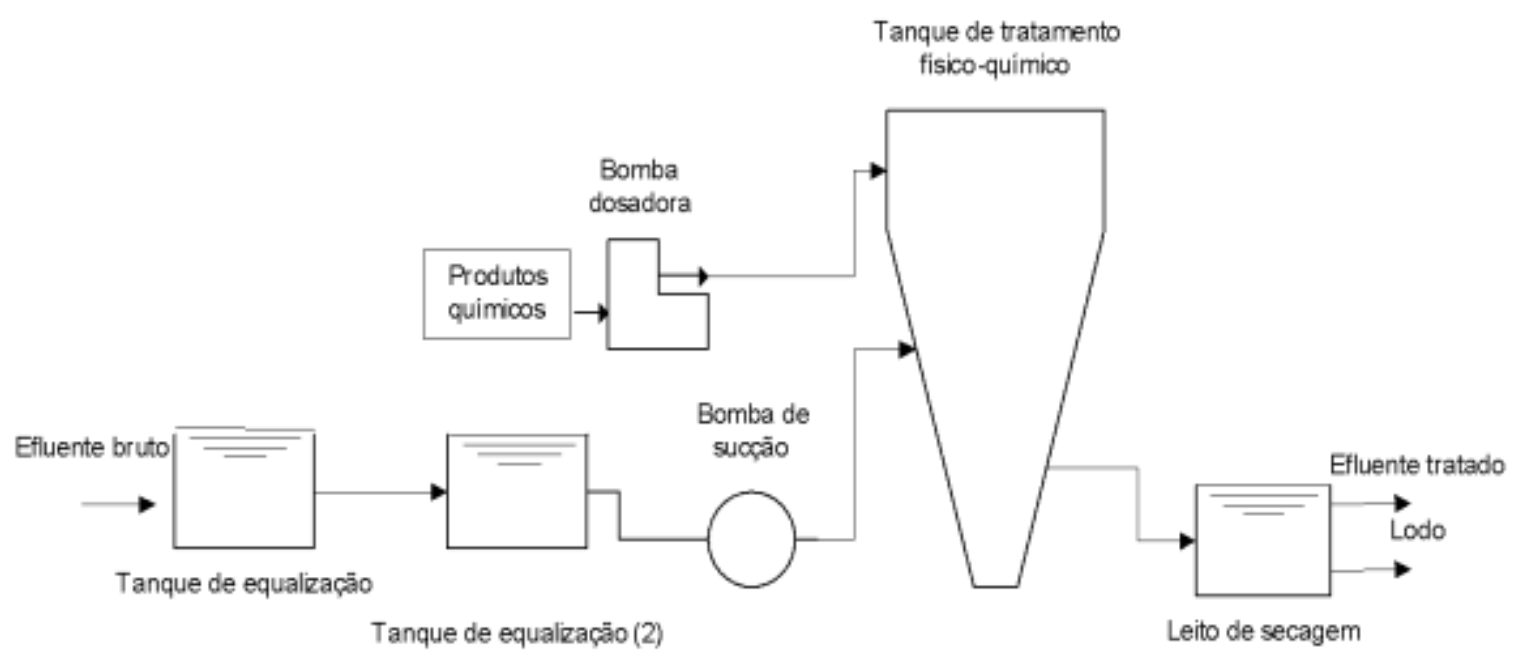

Fonte: Autores.

A unidade funcional adotada será um 1 metro cúbico de efluente tratado e o fluxo de referência adotado foi $1 \mathrm{~m} 3$ de efluente tratado no período de 20 anos. Os dados utilizados foram provenientes do monitoramento de dos parâmetros físico-químicos da Estação de Tratamento de Efluentes (ETE).

\subsection{Inventário}

Os parâmetros utilizados para caracterizar o efluente tratado foram: Demanda Química de Oxigênio (DQO), Demanda Biológica de Oxigênio (DBO) e Óleos Graxas (OG). Os valores médios dos dados de saída do sistema foram calculados durante o período de um ano de acompanhamento, através de relatórios mensais que a lavanderia realizou por meio de empresas terceirizadas. Para o cálculo da carga levou-se em consideração que o sistema foi conservativo, a vazão de entrada foi igual à da saída, para ambos os parâmetros. O período de operação da ETE foi de 20 anos o que corresponde a 175.200 horas. Os produtos químicos utilizados no processo físico-químico pela lavanderia foram: Panfloc TE (Polyaliminium Chloride) categorizado como químico inorgânico e um polímero (polieletrólito) orgânico. Os dados dos consumos diários foram obtidos por Silva (2013) por meio das planilhas eletrônicas que demonstram que o consumo por hora do Panfloc é de $0,3 \mathrm{~kg} \cdot \mathrm{m}^{-3}$ e o do polímero: $0,00004 \mathrm{~kg} \cdot \mathrm{m}^{-3}$.

A aplicação da energia elétrica no processo de tratamento deve-se ao fato de que a ETE utiliza dois tipos de bombas, o que contabilizou 27.116,256 KWh ao longo dos 20 anos de operação. O banco de dados utilizado no software foi por meio do Ecoinvent ${ }^{\circledR}$ disponível no próprio programa. 


\subsection{Categorias de impacto}

A escolha do método de análise depende das categorias pretendidas no estudo e que levam em consideração métodos de pontos intermediários (Midpoint) e de ponto final (Endpoint) que apresentam diferentes níveis de detalhes. Sua diferenciação está na observação da cadeia causa e efeito. O ponto médio analisa o impacto ambiental mais cedo ao longo da cadeia de causa-efeito enquanto o de ponto final ao fim dessa cadeia (Pré Consultants, 2016). O método escolhido foi o Recipe Midpoint (I) V1.10/ World Recipe I por representar as categorias de impacto pertinentes ao estudo da disposição final dos efluentes nos corpos hídricos da região, problemas que afetam a saúde humana e a vida marinha. De acordo com Mendes (2013) os dados de normalização são disponíveis para a Europa e para o mundo a partir dos anos 2.000. As categorias analisadas foram: mudanças climáticas, eutrofização de água doce, eutrofização marinha, toxicidade humana e ecotoxicidade de água doce.

\section{Resultados e discussões}

O tratamento de $1 \mathrm{~m} 3$ de efluente oriundo do beneficiamento de peças de jeans ao longo de vinte anos nas condições estabelecidas no escopo do trabalho, permitiu a obtenção dos resultados gerais dos impactos apresentados na tabela 1 e os gráficos por categoria de impacto através da figura 6: 
Tabela 1 - Resultados gerais das categorias de impacto

\begin{tabular}{|c|c|c|c|c|c|}
\hline Categoria de impacto & Unidade & Total & $\begin{array}{l}\text { Químicos } \\
\text { Orgânicos }\end{array}$ & $\begin{array}{l}\text { Químicos } \\
\text { Inorgânicos }\end{array}$ & Eletricidade \\
\hline Mudanças Climáticas & $\mathrm{kg} \mathrm{CO} 2 \mathrm{eq}$ & 0,1946 & $2,742 \mathrm{E}-05$ & 0,1798 & 0,0147 \\
\hline $\begin{array}{l}\text { Eutrofização de água } \\
\text { doce }\end{array}$ & $\mathrm{kg} P$ eq & $7.21 \mathrm{E}-06$ & $4,511 \mathrm{E}-10$ & $6.877 \mathrm{E}-06$ & $3,285 \mathrm{E}-07$ \\
\hline Eutrofização Marinha & $\mathrm{kg} \mathrm{N} \mathrm{eq}$ & $3,45 \mathrm{E}-06$ & 2,230 E-09 & $3,351 \mathrm{E}-05$ & $1,859 \mathrm{E}-06$ \\
\hline $\begin{array}{l}\text { Toxicidade Humana } \\
\text { Ecotoxicidade de Água }\end{array}$ & $\mathrm{kg} 1,4-\mathrm{DB}$ eq & 0,0218 & 2,8545 E-07 & 0,0216 & 0,0001 \\
\hline doce & $\mathrm{kg} \mathrm{1,4-DB} \mathrm{eq}$ & 0,0003 & 2,3942 E-07 & 0,0003 & 6,609 E-06 \\
\hline
\end{tabular}

Figura 6 - Resultados por categoria de impacto

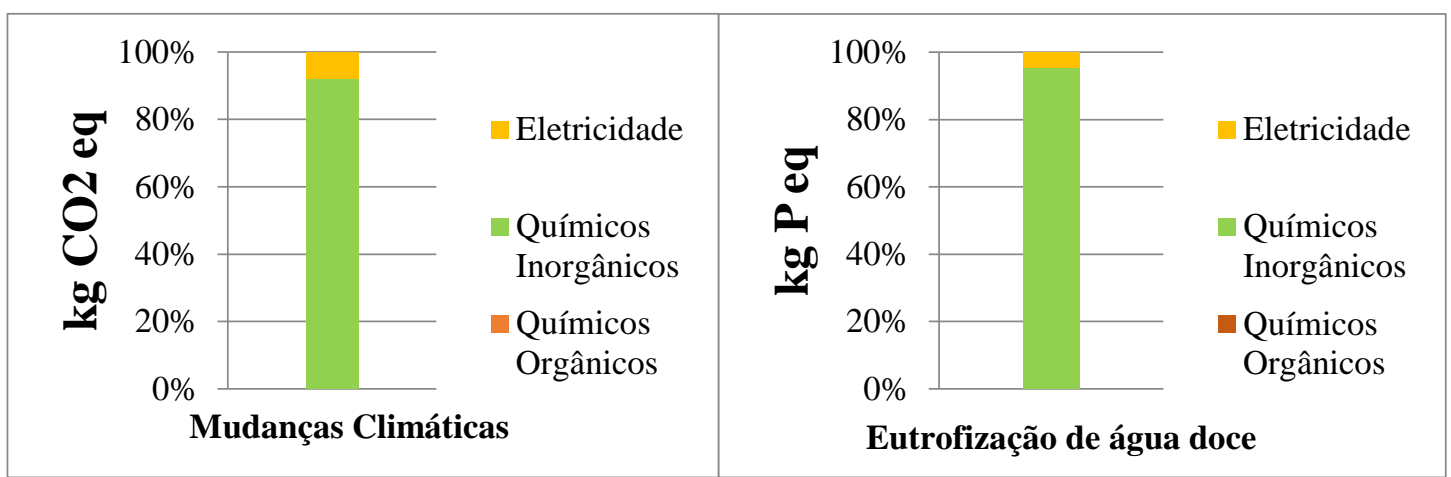

6a)

6b)

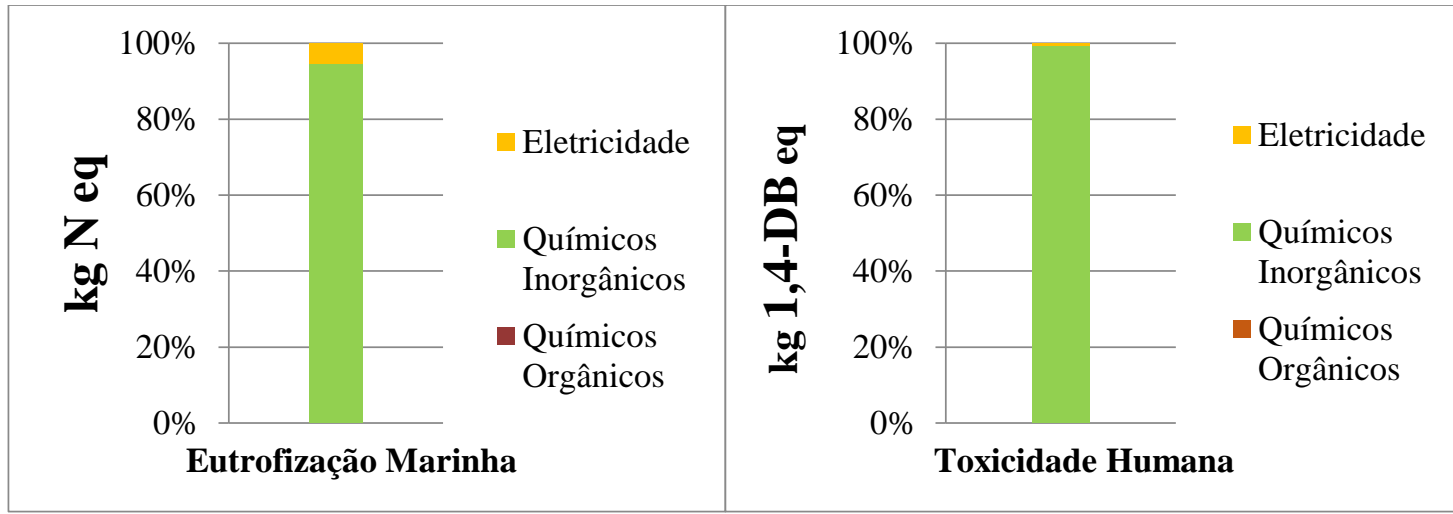

6c)

6d)

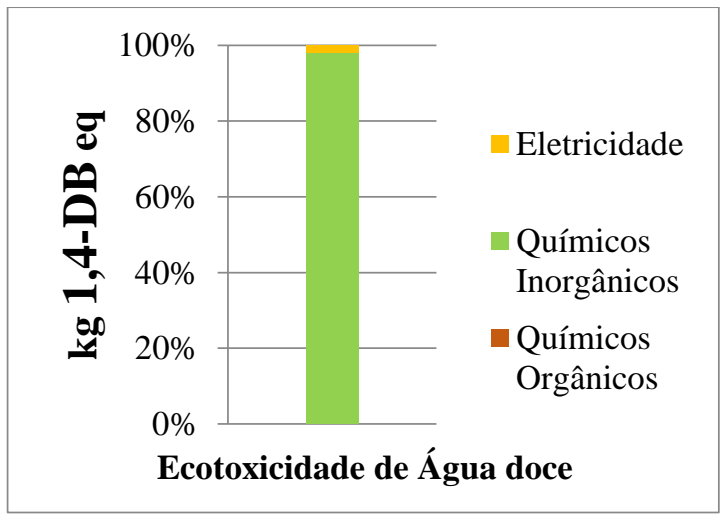

6e)

Fonte: Autores. 
A partir dos dados pôde-se inferir que o químico inorgânico é o principal poluente nas categorias do estudo, o que representa impactos a cima de $90 \%$. Esse fato foi constatado pelo uso da solução de hipoclorito de sódio na fase de operação, através do estudo desenvolvido por Lopes (2014) que identificou impactos consideráveis nas categorias analisadas de depleção abiótica, acidificação e aquecimento global, tendo como menor contribuição na categoria de Eutrofização. O químico orgânico é identificado em parcelas inferiores a $1 \%$. Na categoria de mudança climática (Figura 6a) o químico inorgânico contribui com 92,4\% de emissões de CO2 para a atmosfera, enquanto a energia elétrica contribui com 7,59\% dessas emissões, o químico orgânico representa uma parcela inferior a 1\%. Na categoria de eutrofização de água doce (Figura 6b) esses impactos são potencializados pelo químico inorgânico que representam 98,4\% de emissão de Fósforo (P) e Fosfato (PO43-) no meio aquático. Na eutrofização marinha (Figura 6c) os principais impactos causados pela fixação de Nitrogênio (N) é o químico inorgânico responsável por 97,5\% seguido pela energia elétrica com 2,4\%. As categorias de toxicidade humana e ecotoxicidade de água doce são medidas em diclorobenzeno, onde os químicos inorgânicos representam 95,4\% e 94,5\% respectivamente do impacto ao longo de 20 anos de operação da ETE. A fase de operação do tratamento é considerada como a mais impactante, quando comparada a construção, verificada através dos estudos de Gallego, Hospido, Moreira e Feijoo (2008); Renou, Thomas, Aoustin e Pons (2008); Foley, Hassad, Hartleyb e Lant, (2010); Lopsik, (2013); e Lopes (2014). Os aumentos dos impactos ambientais da ETE são causados proporcionalmente com acréscimo dos produtos químicos, o que faz com que a qualidade do efluente seja melhor (Lopes, 2014).

\section{Conclusões}

Os resultados do estudo demonstraram que os produtos químicos inorgânicos estão presentes em todas as categorias de impactos e em percentuais acima de $90 \%$, o que sugere a substituição por produtos menos nocivos ao meio ambiente. A eutrofização é potencializada com o aumento de nutrientes no meio aquático com a família de produtos fosforados. A energia elétrica apresentou impactos significativos, o que sugere uma redução no tempo de uso. Outra sugestão seria adotar métodos que utilizem a gravidade, por exemplo, para transportar o efluente dos tanques de equalização para as próximas etapas do processo da ETE. A ferramenta de Análise de Ciclo de Vida permitiu identificar os principais impactos ambientais associados ao processo de tratamento, através de dados quantitativos para o apoio da tomada de decisão por parte dos envolvidos na organização com a finalidade de proteger a saúde dos trabalhadores, bem como a qualidade ambiental e de vida da população do entorno. 


\section{Referências}

Associação Brasileira da Indústria Têxtil [ABIT]. (2017). Dados de denim e calças jeans produção, faturamento e exportação. São Paulo, 2017. 1 p. Recuperado em 5 fevereiro, 2017 de http://www.abit.org.br/cont/quemsomos

Associação Brasileira da Indústria Têxtil [ABIT]. (2015). Segundo maior produtor têxtil da região Nordeste, PE discutirá competitividade. Recuperado em 13 fevereiro, 2018, de http://www.abit.org.br/noticias/segundomaior-produtor-textil-da-regiao-nordeste-pe-discutira-competitividade.

Associação Brasileira da Indústria Têxtil [ABIT]. (2016). "Agreste TEX" 2016 movimenta mercado têxtil do Nordeste. Recuperado em 13 fevereiro, 2018 de http://www.abit.org.br/noticias/agreste-tex-2016movimenta-mercado-textil-do-nordeste.

Associação Brasileira de Normas Técnicas (2009). NBR ISO 14040: gestão ambiental: avaliação do ciclo de vida: princípios e estrutura. Rio de Janeiro, 2009. 21p.

Almeida, R. G., \& Bessa, W. (2015) O. Estudos sobre análise do ciclo de vida e sua aplicação para concreto estrutural. Congresso Técnico Científico da Engenharia e da Agronomia (CONTECC). Recuperado em 3 junho, 2017, de http://acv.ibict.br/banco-nacional/o-que-e-sicv/.

Bankuti, S. M. S., \& Bankuti, F. I. (2014). Gestão ambiental e estratégia empresarial: um estudo em uma empresa de cosméticos no Brasil. Gest. Prod. [online]., vol.21, n.1, pp.171-184. ISSN 0104530X. http://dx.doi.org/10.1590/s0104-530X2014000100012.

Both, F., \& Fischer, A. (2017). Gestão e contabilidade ambiental. Unoesc \& Ciência-ACSA, 8(1), 49-58

Brito, G. A. (2013). Sustentabilidade: um desafio para as lavanderias industriais. Revista de Design Inovação e Gestão Estratégica. v. 4, n. 02, ago.

Claudino, E. S.; \& Talamini, E. (2013). Análise do Ciclo de Vida (ACV) aplicada ao agronegócio - Uma revisão de literatura. Revista Brasileira de Engenharia Agrícola e Ambiental, vol.17 no. 1 Campina Grande. Janeiro.

Confederação Nacional da Indústria [CNI]. (2017). Perfil da indústria nos estados. Recuperado em 13 fevereiro, 2018, de http://perfilestados.portaldaindustria.com.br/estado/pe

Coelho Filho, O., Saccarro Junior, N. L., \& Luedemann, G. (2015). O Uso da análise de ciclo de vida (ACV) nas políticas públicas: condicionantes e estratégias de implementação da ACV no Brasil. Instituto de Pesquisa Econômica Aplicada (Ipea).

De Souza. C. G., \& Barbastefano R. G. (2011). Knowledge diffusion and collaboration networks on life cycle assessment. Int Jornaul of Life Cycle Assessment 16: 561-568.

Figueiredo, G. C., \& Cavalcante, A. L. B. L. (2010). Calça jeans - produtividade e possibilidades sustentáveis. Revista Projética, v. 1, n. 1, dez, p. 128-145.

Foley, J., De Haasa D., HARTLEYB K., \& LANT, P. (2010). Comprehensive life cycle inventories of alternative wastewater treatment systems. Water Research, 44, 1654-1666.

Fuchs, V. J., Mihelcic, J.R., \& Gierke J.S. (2011). Life cycle assessment of vertical and horizontal flow constructed wetlands for wastewater treatment considering nitrogen and carbon greenhouse gás emissions. Water Research, 45, $2073-2081$

Gallego, A., Hospido A., MOREIRA M.T., \& FEIJOO G. (2008). Environmental performance of wastewater treatment plants for small populations. Resources, Conservation and Recycling, 52, 931-940.

Hospido, A., Moreira, M. A., \& Feijoo, G. (2007). A Comparison of Municipal Wastewater Treatment Plants for Big Centres of Population in Galicia (Spain).The International Journal of Life Cycle Assessment, 13, 57-64.

Instituto Brasileiro de Geografia e Estatística [IBGE]. (2014). Censo demográfico: Cidades. Recuperado em 29 de julho, 2018, de https://www.ibge.gov.br.

Lopes, C. S. D. (2012). Análise ambiental da fase de acabamento do jeans. Interfac EHS-Revista de Saúde, Meio Ambiente e Sustentabilidade, v. 6, n. 3.

Lopes, T. A. S. (2014). Avaliação do ciclo de vida de uma ETE composta por reator UASB seguido de Wetlands construídos. Dissertação de mestrado, Universidade Federal da Bahia. Escola politécnica, Brasil. Disponível em: http://www.maasa.eng.ufba.br/dissertacoes/avaliacao-do-ciclo-de-vida-de-uma-ete-composta-porreator-uasb-seguidos-de-wetlands-con

Lopes, T. A. S.; KIperstok, A., Zanta, V. M., \& Queiroz, L. M. (2017). Revisão crítica da literatura sobre aplicação da avaliação de ciclo de vida ao tratamento de esgotos. Revista DAE.

Lopsik, K. (2013). Life cycle assessment of small-scale constructed wetland and extended aeration activated sludge wastewater treatment system. International Journal of Environmental Science and Technology, 10, 1295-1308. 
Marques, V. M., Gomes, L. P., \& Kern, A.P. (2016). Environmental assessment of the life cycle of cementitius roofing sheets with asbestos fibers or with polypropylene fibers. Ambiente Construído, v. 16, n. 1, p. 187-201.

Martins, P. S., Escrivao Filho, E., \& Nagano, M. S. (2016). Fatores Contingenciais da Gestão Ambiental em Pequenas E Médias Empresas. RAM, Rev. Adm. Mackenzie[online], vol.17, n.2, pp.156-179. ISSN 15186776. http://dx.doi.org/10.1590/1678-69712016/administracao.v17n2p156-179.

Mendes, N.C. (2013). Métodos e modelos de caracterização para avaliação de impacto do ciclo de vida: análise e subsidies para a aplicação no Brasil. Dissertação de mestrado, Programa de pós-graduação em Engenharia de Produção. Escola de Engenharia de São Carlos. USP. Disponível: http://www.teses.usp.br/teses/disponiveis/18/18156/tde-15102013-085143/pt-br.php

Pré Consultants (2016). Introduction to LCA with SimaPro 8. Califórnia.

Ratiu, M., Bota, S. R., \& Suteu, C. (2008). Impact of the textile industry on human and environmental health. In Annals of the International Scientific Symposium Innovative Solutions for Sustainable Development of Textiles Industry. Faculty of Textiles and Leatherwork, University of Oradea, Romania, p. 412-417.

Renou, S., Thomas, J. S., Aoustin, E., \& Pons, M. N. (2008). Influence of impact assessment methods in wastewater treatment LCA. Journal of Cleaner Production, V. 16, p. 1098 - 1105,

Sant'ana, P. H. de M. (2010). Oportunidades de eficiência para indústria: setor têxtil. Brasília: CNI.

Serviço Brasileiro de Apoio às Micro e Pequenas Empresas [SEBRAE]. (2015). Critérios de classificação de empresas. Recuperado em: 4 de junho, 2017 de http://www.sebrae-

sc.com.br/leis/default.asp?vcdtexto $=4154$.

Silva Filho, A. R. A. (2013). Desenvolvimento de sistema simplificado de gestão ambiental aplicado à micro e pequenas empresas de beneficiamento de jeans. Tese de doutorado - Recife: O Autor, 215 folhas. Disponível em: https://repositorio.ufpe.br/handle/123456789/12878

Ueda, A. C. (2006). Aplicação de micelas reversas na remoção de corantes têxteis catiônicos. Dissertação de mestrado. Engenharia Química, Universidade Federal de Santa Catarina, Florianópolis, fev., 70 p. Disponível em: https://repositorio.ufsc.br/handle/123456789/89344

Tillman, A.M., Svingby M., Lundström H. (1998). Life Cycle Assessment of Municipal Waste Water Systems. The International Journal of Life Cycle Assessment, 3, 145 - 157.

Willers, C. D., Rodrigues, L. B., Silva, C. Alves da. (2013). Avaliação do ciclo de vida no Brasil: uma investigação nas principais bases científicas nacionais. Prod., São Paulo, v. 23, n. 2, p. 436-447.

Zapparoli, S. S. da Silva. (2011). Desenho da Metodologia da Avaliação do Ciclo de Vida (ACV) do Etanol Combustível pelo método CML 2000 com SimaPRO. 3 International workshop advances in cleaner production. São Paulo.

Recebido em: 20 fev. 2018 / Aprovado em: 20 ago. 2018

\section{Para referenciar este texto}

Duarte, A. D., \& Silva, G. L. da (2020). Aplicação da ferramenta de Análise de Ciclo de Vida (ACV) no processo de tratamento de efluentes em uma lavanderia de beneficiamento de jeans. Exacta, 18(2), 355-367. https://doi.org/10.5585/ExactaEP.v18n2.8370. 